\title{
MOTION ANALYSIS OF A LOW COST CUSTOMIZED A-SCAN NON DESTRUCTIVE TESTING UNIT
}

\author{
M.N. M. Zukri and E. A. Bakar \\ ${ }^{1}$ School of Aerospace Engineering, \\ Universiti Sains Malaysia, \\ *Email: meelmi@usm.my
}

\begin{abstract}
This study introduced a new design of a low-cost customized A-scan Non Destructive Testing (NDT) unit using microcontroller-based scanning motion. The scanning unit from previous research has limitations in scanning envelope area and ability of detection. It can only detect large defects. To solve the limitations mentioned above, the purpose of this study is to develop a device with lower cost, more appropriate size of scanning envelop area, and ability to detect internal layer defections. The mechanism of this machine is achieved by using 3 NEMA 17 bipolar stepper motors for the movement of every axis. MATLAB is used in this machine for the purposes of signal acquisition, signal analysis and to control the linear motions. Since this machine is small in size $(40 \mathrm{~cm} x$ $27 \mathrm{~cm} \times 72 \mathrm{~cm}$ ), it can be used for small scale testing and analysis. As compared with current product, this machine is more portable and affordable. Thus, it is more convenient in the areas of research and education. The contributions of this machine is providing an affordable machine for advancement research field and enhancement quality inspection in manufacturing industries.
\end{abstract}

Keywords: Non Destructive Testing (NDT), scanning motion, signal acquisition, signal analysis.

\section{INTRODUCTION}

In advanced technology applications such as aerospace and industrial with emphasis on economics and safety, Non-destructive testing (NDT) is a practical method to validate and inspect the composite without compromising the integrity of the material. Commonly NDT techniques are Acoustic Emission Testing (AET), Acoustic Resonance Testing (ERT), Electromagnetic Testing (ET), Infrared Testing (IT), Magnetic Particle Testing (MT), Radiographic Testing (RT), Ultrasonic Testing (UT) and Visual Testing (VT). Ultrasonic Testing is the most widely technique used for the inspection of composite. [1] Currently, The existing product available for Ultrasonic Testing (UT) is quite expensive and the size is larger. Thus, it is inconvenient for the research and educational purpose. The previous researcher has develop low cost and small size of scanning unit. However, the scanning unit from previous researcher has limitations in scanning envelope area and ability of detection which can only detect the large defect. The aim of this work is to develop a device with lower cost, more appropriate size of scanning envelop area, and ability to detect internal layer defections. A high specification transducer which is $2.25 \mathrm{MHz}$ immersion type is used to improve the capability of inspection to detect interlayer defect. The data acquire from hardware Arduino is analyses and the scanning result is evaluated. This data is evaluated by performing software using MATLAB programs. 
Composite material is widely used in aircraft industries. In critical structural applications, it is more important for ensure the structural integrity during manufacturing composite structure. For composite materials, much of the NDT is conducted either during or immediately after manufacture of the component and the work is looking for defects. Usually, defect of composites can occur by impact, environmental effects or from unidirectional or cyclic load application, all of which have different effects on the defects already present or all different types of defect in one time. Thus, the complexity of the advanced composite materials manufacturing and

Composite in service maintenance represents challenges in developing optimized nondestructive tools and tests. Traditional metals based NDT methods are inappropriate and often misleading when applied to anisotropic and inhomogeneous composite materials. In advanced technology applications such as aerospace, it is critical to use and develop new practical composites NDT methods. Composite NDT in modified traditional and new tools consists ultrasonic, $\mathrm{x}$ - ray, acoustic emission, thermal, optical, electrical and a variety of hybrid methods. Ultrasonic pulse-echo is a well-established and widely used nondestructive testing technique. A pulse of ultrasonic energy, typically a few microseconds, is transmitted into the specimen in a direction normal to the surface. Figure 1 shows a typical pulse-echo set-up for a submerged immersion test.

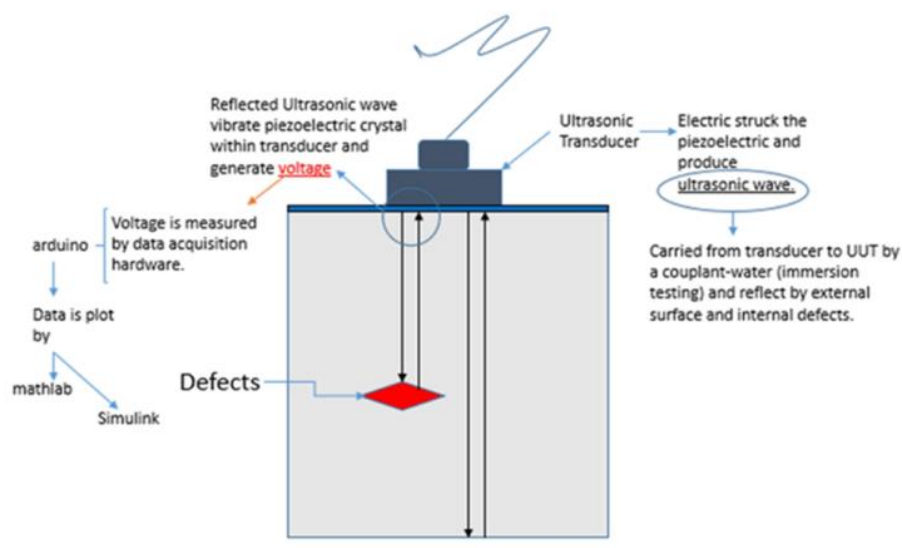

Figure 1. Immersion pulse-echo test with submerged specimen

Those signals which travel back towards the probe are detected and the position and size of a flow is determined from the total pulse travel time and detected amplitude respectively. This is the 'A-scan' display and it consists of a series of peaks, the position of which along the horizontal axis can be calibrated in terms of the depth in the composite. The amplitude of each echo will give some indication of the size and nature of the reflector, which might be a flaw or a specimen boundary. Figure 2 (a) shows a typical Ascan display from pulse-echo immersion test. In this display, the echoes from different features within the composite do not merge (i.e. they are well resolved) because the pulse duration is short to avoid it interacting with any of the features at the same time. The first peak is due to electrical pulse used to excite the transducer also called 'main bang' and is convenient reference for the following peaks. There are the flaw reflection in the front surface of the component and the rear surface of the component also known as back surface reflection. 


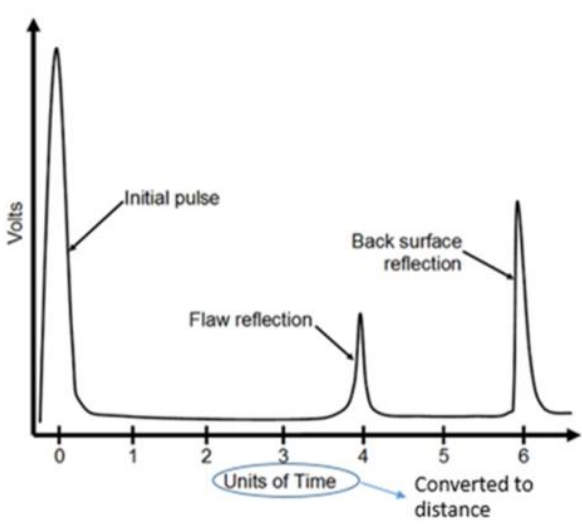

(a)

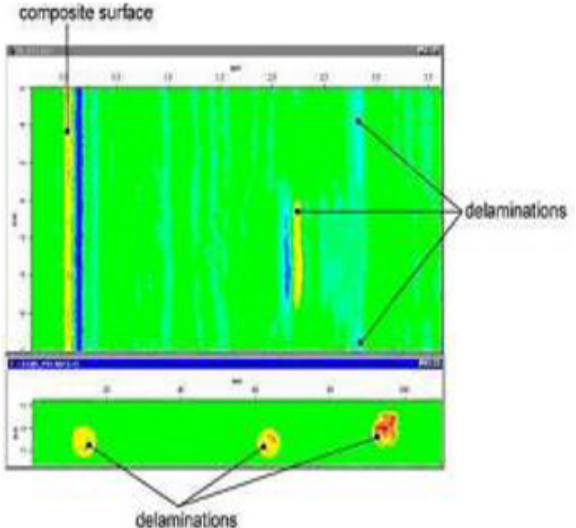

(b)

Figure 2, (a) Diagrammatic A-scan display for a typical pulse-echo immersion test and (b)Ultrasonic image of delamination in carbon fibre composite (B and $\mathrm{C}$ scans)

Typically immersion testing is used to carry out area scans where the ultrasonic data can be represented in ways that make it easier to interpret. In the 'B-scan' display a 2D 'slice' through the specimen is produced by scanning the probe along the surface and capturing an A-scan at each point along the scanning direction. A 'D-scan' is also slice through the specimen taken at a fixed scanning point in each of a set of parallel B-scans.

In B and D-scans, the amplitude at each point is displayed as a colour or a greyscale value according to a predetermined pallette. In general, the higher the amplitude the brighter or more intense the displayed point. C-scan may be thought of as 'Top down' or 'Plan' views of the component. Here the A-scan is 'gated' to display either the amplitude or the depth of signal occurring within a predefined depth range within the component. Figures shows a C-scan of a multi-ply CRP composite with artificially induced delamination (Teflon inserts). The upper image represents a B-scan and the lower image represents a $\mathrm{C}$-scan as shown in figure $2(\mathrm{~b})$.

\section{METHODOLOGY}

\section{Design of Experiment}

In this section, the experimental setup for project went further into the idea of improving Ultrasonic Testing machine for the general users, not only low-income ones. What started as a simple afterthought has now become a mission that must be completed without failure. A vision of an Ultrasonic Testing machine that is easy to use, light and cheap is produced. And thus, it moved on to improvise more on design. Morphological Chart is a table based on the function analysis. On the left side of the chart the functions are listed, while on the right side, different mechanisms which can be used to perform the functions listed are drawn, the flow of overall process is shown in figure 3(a), while the idea to compare alternative concept is shows in figure 3(b).

By through process design, the best alternative design 3 is selected as a final design. After that, fabrication process is start with dividing a parts of work. Some of works was completely done in mechanical workshop and the remaining is done in aerospace laboratory. 


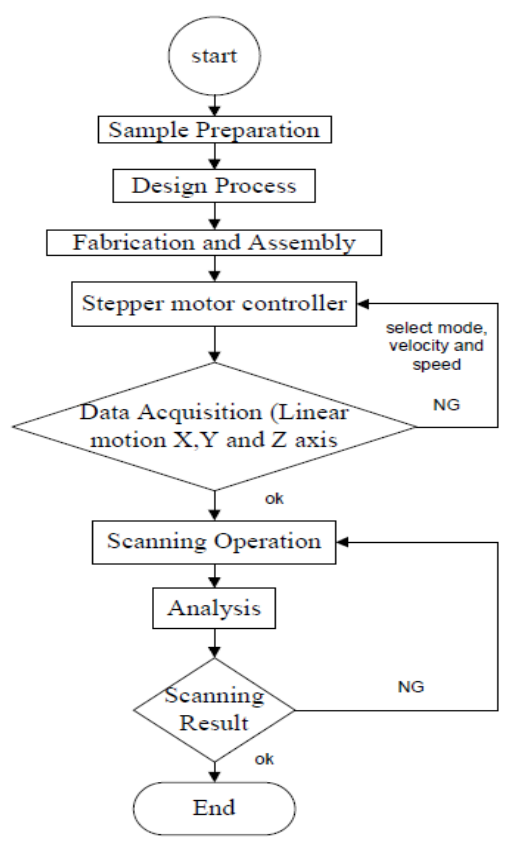

Figure 3. (a) Overall process flow

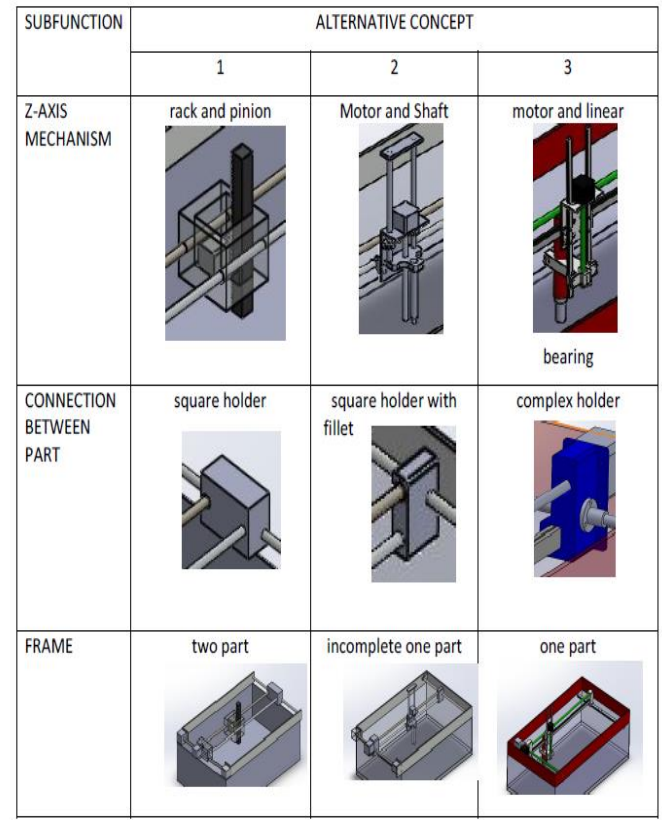

(b) Alternative design

\section{Motor Performance and Validation Test}

The positional accuracy of the stepper motors will be high only when its step angle is very small. Hence for the inspection purpose, stepper motor is the best choice as it can offer small step angles in the range of 0.50 to 1.8 mechanical degrees. Thus, one of the experiment is set up to analyses the performance of motor. The experiment is to observe whereas the motor with or without loading influenced the speed performance of motor. One experimental is set up. The figure 4 (a) and (b) below shows the motor performance and validation test.

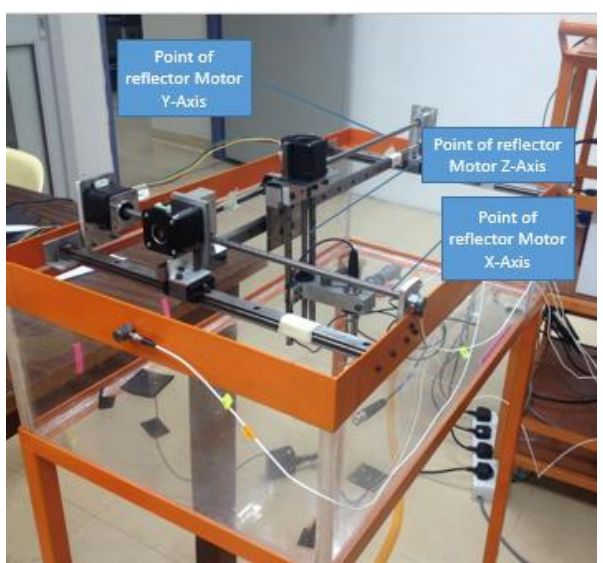

Figure 4. (a) The point of reflector for 3 axis

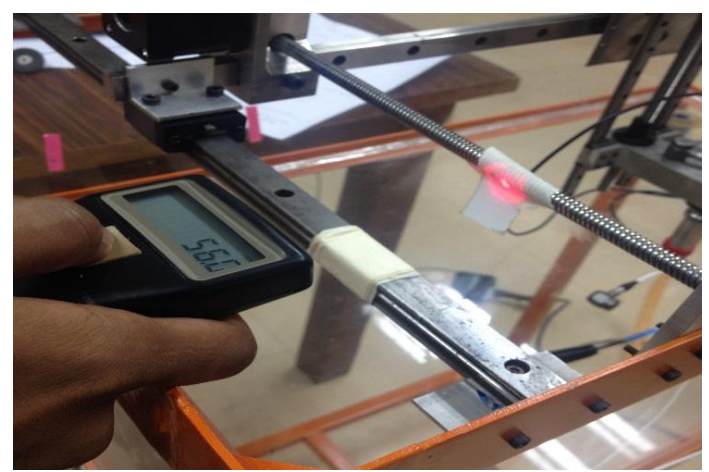

(b) the tachometer measure the speed of motor $\mathrm{X}$-axis

The reflector is attach to the thread. When motor is running, the reflector will rotate together and give the reading to the tachometer. The reading is taken as a data and efficiency of the stepper motor is calculated. 


\section{Fatigue Analysis thru analytical Approach for Motor}

In this section, calculated the displacement, von-Mises (equivalent stress) $\left(\delta_{e q}\right)$, and factor of safety $\left(f_{s}\right)$. Then, this section also to validate design stresses to compare meanstress value of material through graph as shown in figure 5. This curve is valid for steels. The aim of this analysis to prove the thread shaft instead of length, diameter and type of material is selected for infinite life. To design for infinite life, the endurance limit become the criteria of failure. At the end, the number of load cycles is calculate and the result should be exceed than $1 \times 10^{6}$ cycles in order to withstand the infinite life of cycles. The example of travelling Y-Axis shown in table 1.

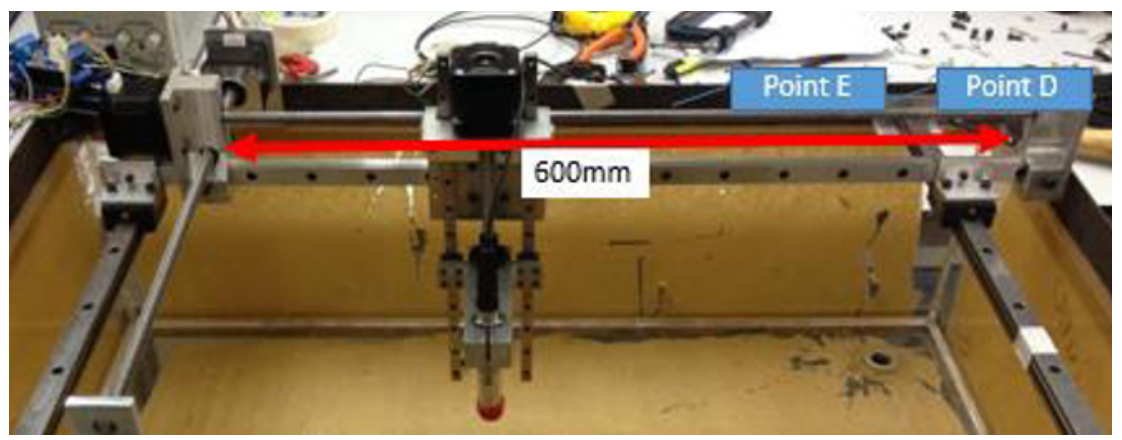

Figure 5. Example of Travelling motor $600 \mathrm{~mm}$

Table 1. Properties of Y-axis

\begin{tabular}{|c|c|c|c|c|}
\hline Motors & Weight (N) & Length (m) & Diameter (m) & $\begin{array}{c}\text { Yield Strength } \\
\left(\mathrm{N} / \mathrm{m}^{2}\right)\end{array}$ \\
\hline Y-Axis & 9.04 & 0.60 & 0.008 & 172 \\
\hline
\end{tabular}

Table 2. Analytical Approach

\begin{tabular}{|c|c|}
\hline Variable (analytical approach) & Value \\
\hline Displacement, $\Delta L$ & $0.157 \mathrm{~mm}$ \\
\hline Von Mises /equivalent stress, $\delta_{m}$ & $38.26 \mathrm{~N} / \mathrm{mm}^{2}$ \\
\hline Factor of Safety, $f_{s}$ & 1.72 \\
\hline
\end{tabular}

The thread shaft is a rotating part that driven by motor is used to transmit power or motion. For the thread use in this machine, it consists 3 parts that associate with axis $\mathrm{X}, \mathrm{Y}$, and Z-axis. However, the critical part will be on the $\mathrm{Y}$-axis thread because it is suffer the load from Z-axis and also the thread itself. Analytical Approach value is shown in table 2. For the thread on Y-axis, according to Shigley 8th edition [5], typically the static stresses are not significant in thread or shaft design because fatigue and speeds play a more important role in this design. Since, thread shafts is rotate, there is a strong likelihood of fatigue issues.

The fatigue life prediction is performed based on finite element analysis and analytical method. Using the constant amplitude loading, the fatigue life of the thread shaft has been predicted. This analysis will give information for the fatigue life of the thread 
shaft that are used in this machine. The comparison of simulation and analytical approach is presented in table 3 .

Table 3. Comparison Simulation and analytical approach

\begin{tabular}{|c|c|c|c|}
\hline Type & $\begin{array}{c}\text { Simulation } \\
\text { Approach }\end{array}$ & $\begin{array}{c}\text { analytical } \\
\text { approach }\end{array}$ & $\begin{array}{c}\text { Percentage } \\
\text { difference, } \%\end{array}$ \\
\hline Displacement, $\Delta L$ & $0.101 \mathrm{~mm}$ & $0.157 \mathrm{~mm}$ & $36 \%$ \\
\hline $\begin{array}{c}\text { Von Mises } \\
\text { /equivalent stress, } \delta_{m}\end{array}$ & $41.51 \mathrm{~N} / \mathrm{mm}^{2}$ & $38.26 \mathrm{~N} / \mathrm{mm}^{2}$ & $8.5 \%$ \\
\hline Factor of Safety, $f_{s}$ & $\begin{array}{c}>1 \text { (blue } \\
\text { color) }\end{array}$ & 1.72 & - \\
\hline
\end{tabular}

By comparing the above results, Von-Mises stress value by analytical approach $\delta_{m}=38.26 \mathrm{~N} / \mathrm{mm}$ which are nearly close by using FEA approach having difference of $8.5 \%$ less than $10 \%$ which is acceptable range. The fatigue factor of safety calculated from analytical approach is 1.72 whereas the FEA approach give the FOS larger than 1 . It is means that the design has a correct design and prevent to failure.

\section{RESULTS AND DISCUSSION}

\section{Linear motion Analyses}

Generally, to check the performance of motor, the experiment of speed rotation of motor is conduct as a mention in previous section. It is to checking the load that adding in particular point is affecting the performance of motor. The result is provides in table 4 and 5 .

Table 4. Performance of motor without load

\begin{tabular}{|c|c|c|c|c|c|c|c|c|}
\hline \multicolumn{9}{|c|}{ WITHOUT LOAD } \\
\hline \multirow{2}{*}{ Motor } & \multirow{2}{*}{ Volt } & \multirow{2}{*}{ Current } & \multicolumn{5}{|c|}{ Speed } & \multirow{2}{*}{ Efficiency } \\
\hline & & & 1 & 2 & 3 & Average & Input & \\
\hline $\mathrm{x}$ & \multirow{3}{*}{$5 \mathrm{~V}$} & \multirow{3}{*}{$1.5 \mathrm{~A}$} & 56.3 & 57 & 56.3 & 56.53 & 200 & 28.27 \\
\hline $\mathrm{Y}$ & & & 56.3 & 56.4 & 56.8 & 56.50 & 200 & 28.25 \\
\hline Z & & & 56.4 & 56.3 & 56 & 56.23 & 200 & 28.12 \\
\hline
\end{tabular}

Table 5 Performance of motor with load

\begin{tabular}{|c|c|c|c|c|c|c|c|c|}
\hline \multicolumn{9}{|c|}{ WITH LOAD } \\
\hline \multirow{2}{*}{ Motor } & \multirow{2}{*}{ Volt } & \multirow{2}{*}{ Current } & \multicolumn{5}{|c|}{ Speed } & \multirow{2}{*}{ Efficiency } \\
\cline { 4 - 9 } & & 1 & 2 & 3 & Average & Input & \\
\hline $\mathrm{X}$ & \multirow{3}{*}{$5 \mathrm{~V}$} & \multirow{3}{*}{$1.5 \mathrm{~A}$} & 56.7 & 56.5 & 56.6 & 56.60 & 200 & 28.30 \\
\cline { 4 - 9 } & & 56.5 & 56.3 & 56.5 & 56.43 & 200 & 28.22 \\
\cline { 4 - 9 } & & 56.4 & 56.5 & 56.1 & 56.33 & 200 & 28.17 \\
\hline $\mathrm{Z}$ & & & &
\end{tabular}


It is clear from the above table 5 shown results that the performance of motors are not affected by the load attaching on the thread of the motor. The average speeds of all the conditions is nearly in range of 56-57 rpm. At last, the efficiency of the stepper motor roughly at $28 \%$. According to the previous researcher [4], the efficiency of the stepper motor is very low since the purpose for smooth motion and higher torque instead of speeding. So, it will show the load that attach on the thread of motor not effecting the performance itself.

\section{Vibration structure Analysis}

From the data collecting by the software of Integrated Measurement and Control (IMC), the Fourier Fast Transform (FFT) graph has created. The vibration of machine is analyze based on the FFT graph. In figure 6. To compare the effect of vibration on transducer by running motor Y-axis before the machine install the damper and after the machine install the damper. Constant Variables: Power Source 5V, mode of stepper motor (double mode) Manipulated Variables: Condition of machine (with / without damper)
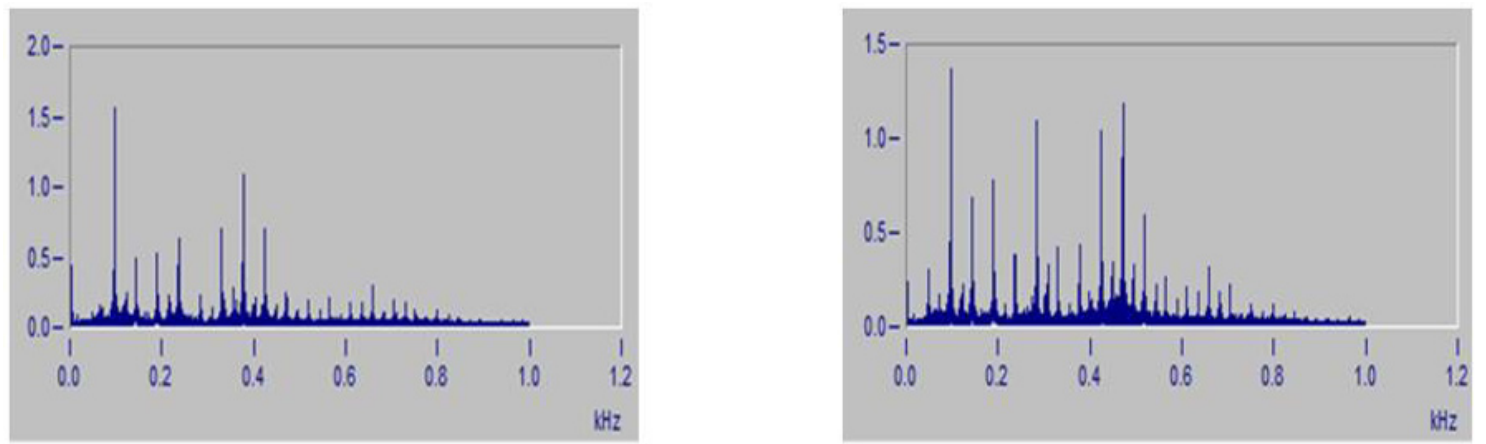

Figure 6. FFT graphs for motor Y-axis without damper (left) and with damper (right)

The aim of this work is to show the vibration on the transducer is reduce at the certain frequency by installing the damper. The transducer should prevent from vibrate in order to ensure the signal on the monitor is stable. The motor $\mathrm{Y}$ is selected as the source of vibration because this motor will constantly running during the scanning operation while the other motors is not critical.

By the observation on the FFT graph, it is showing the damping that install on the machine works at the certain frequency. At first, the desire frequency for motor $\mathrm{X}$ to reduce are $0.1 \mathrm{KHz}$ and $0.38 \mathrm{KHz}$. The both frequency has the highest peak of amplitude which is $1.6 \mathrm{~ms}^{-2}$ and $1.1 \mathrm{~ms}^{-2}$. After installing the damper, the both frequency amplitude is reduced to $1.4 \mathrm{~ms}^{-2}$ and $0.4 \mathrm{~ms}^{-2}$.

Thus, the vibration at this frequency is successfully reduce. However, at the lower frequency, the damper is not work as it is practical that the damper is depend on frequency by dynamic stiffness.

\section{Result of Inspection operation}

In this project, the scanning operation is done by motor controller. The scanning is run to detect the defect at the various depth. Firstly, the depth is $2 \mathrm{~mm}, 4 \mathrm{~mm}$ and through hole. The transducer will travel on this path and provide the signal. Every depth give the different signal so it obviously shows the defect. In this operation, the speed is $200 \mathrm{~m} / \mathrm{s}$, 
$200 \mathrm{step} / \mathrm{rev}$. Every $1 \mathrm{~mm}$ require $25 \mathrm{step}$. The length of this specimen is $128 \mathrm{~mm}$, so the step require is 3200 step.
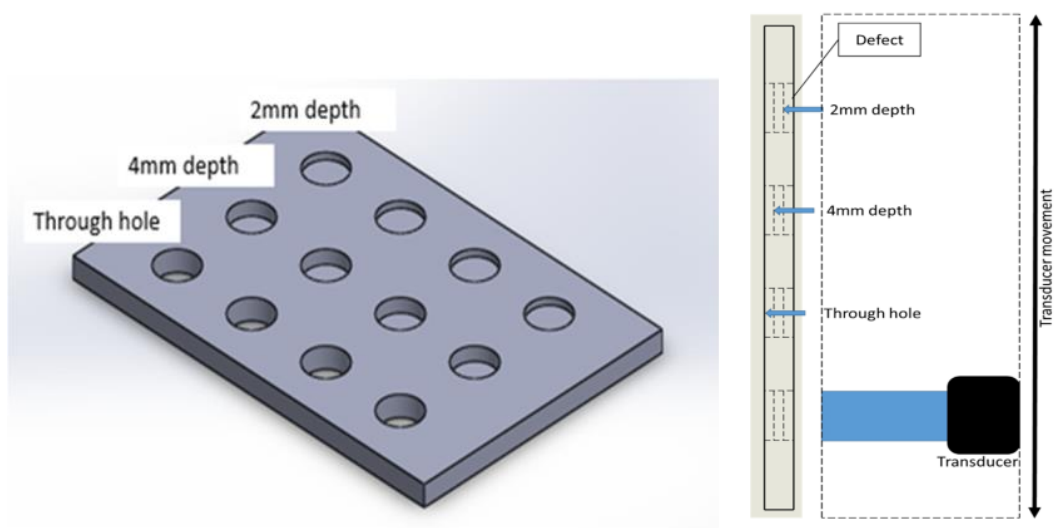

Figure 7 Isometric view of specimen

Figure 8 Cross sectional view of specimen

The figure 7 and 8 above shown the isometric view and the cross sectional view of the specimen. From the cross sectional view, it clearly show the different of depth that experienced by scanning of transducer. There is three different of depth where every depth has four holes. This scanning operation is done and the signal is shown in table 6. The simple sample is prepare for detect defect according to the various depth. In this scanning operation, for every defect that has trace by transducer, it will produce a sound as setting in program. So, it can clearly show that the defect was trace by the machine.

Table 6 Scanning operation

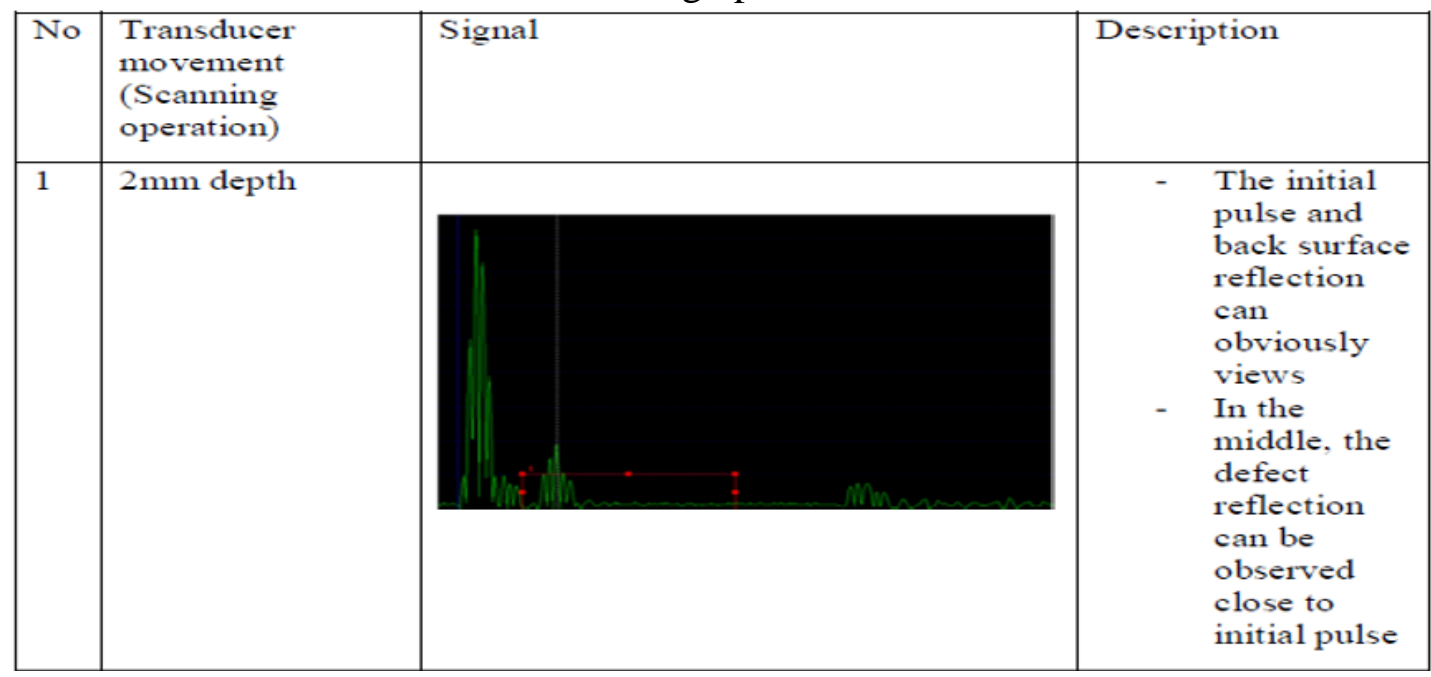

\section{CONCLUSION}

In this study, the main objective is to develop a UT testing device with lower cost, more appropriate size of scanning envelop area, and ability to detect internal layer defections. The overall cost for develop this device is RM27 784.00 which is below to RM 30 000. For the current product, the cost of the device is usually above than RM500 000. Thus, lower cost is achieved. Then, the device also develop at size $40 \mathrm{~cm} \times 27 \mathrm{~cm} \mathrm{x} 72 \mathrm{~cm}$, so that the area of the scanning unit is become increase comparing with previous machine that has been developed in our lab. The mechanism of this machine is achieved by using 3 
NEMA 17 bipolar stepper motors for the movement of every axis. MATLAB is used in this machine for the purposes of signal acquisition, signal analysis and to control the linear motions. For the purpose of ability in defect detection, the high specification transducer which is $2.25 \mathrm{MHz}$ immersion type is selected for the capability of inspection to detect interlayer defect among composite laminates panel. Motion analyses together with vibration analyses is performs and the inspection result should the robustness of this machine to acquire data for Composite Panel as to be costumed made NDT machine.

\section{ACKNOWLEDGEMENTS}

The authors would like to acknowledge Universiti Sains Malaysia and Kementerian Pengajian Tinggi for providing the financial assistance under FRGS and PRGS grants (203/PAERO/6071296 and 203/PAERO/6740041) support for this project.

\section{REFERENCES}

[1] A. El Kouche and H. S. Hassanein, "Ultrasonic non-destructive testing (NDT) using wireless sensor networks," Procedia Comput. Sci., vol. 10, pp. 136-143, 2012.

[2] P. Cawley and R. D. Adams, "Defect types and non-destructive testing techniques for composites and bonded joints," Mater. Sci. Technol., vol. 5, no. 4, pp. 413-425, 1989.

[3] I. G. Scott and C. M. Scala, "A review of non-destructive testing of composite materials," NDT Int., vol. 15, no. April, pp. 75-86, 1982.

[4] M. F. Mahmod, M. Z. M. Pauzi, and E. A. Bakar, "Flatbed Scanner Image and Single Ultrasonic Defect Detection," no. November, pp. 26-27, 2013.

[5] S. R. Doctor, T. E. Hall, and L. D. Reid, "SAFT - the evolution of a signal processing technology for ultrasonic testing," NDT Int., vol. 19, no. 3, pp. 163167, 1986.

[6] P. Gaudenzi, M. Bernabei, E. Dati, G. De Angelis, M. Marrone, and L. Lampani, "On the evaluation of impact damage on composite materials by comparing different NDI techniques," Compos. Struct., vol. 118, pp. 257-266, 2014.

[7] B. Djordjevic, "Nondestructive test technology for the composites," ... Slov. Soc. non-destructive Test., pp. 259-265, 2009.

[8] B. Ren and C. J. Lissenden, "Ultrasonic guided wave inspection of adhesive bonds between composite laminates," Int. J. Adhes. Adhes., vol. 45, pp. 59-68, 20 